\title{
PENGARUH KUALITAS PELAYANAN TERHADAP PENINGKATAN WORD OF MOUTH DI KLINIK PRATAMA 'AISYIYAH MEDICAL CENTER SURAKARTA
}

Amalia Solichati Rizqi ${ }^{1}$, Yudha Wahyu Putra ${ }^{2}$

${ }^{1}$ Dosen Program Studi Fisioterapi Universitas Widya Dharma Klaten

${ }^{2}$ Dosen Program Studi Fisioterapi STIKES ‘Aisyiyah Surakarta

amaliasolichati@gmail.com

\begin{abstract}
ABSTRAK
Latar Belakang : Persaingan dalam usaha jasa pelayanan kesehatan saat ini semakin tinggi. Jasa pelayanan kesehatan berlomba-lomba untuk mendapatkan kepercayaan masyarakat agar masyarakat ikut aktif dan mempercayai pelayanan kesehatan di klinik atau penyedia layanan kesehatan. Strategi marketing model word of mouth merupakan bentuk kegiatan promosi yang sangat di perlukan oleh perusahaan jasa

Tujuan : Mengetahui pengaruh kualitas pelayanan terhadap peningkatan word of mouth di Klinik Pratama 'Aisyiyah Medical Center Surakarta

Metode :. Penelitian ini menggunakan pendekatan kuantitatif dengan analisis statistik regresi dari hasil pengisian kuesioner untuk menguji hipotesis dengan word of mouth sebagai variable dependent dan kualitas pelayanan sebagai variable independent

Hasil : Kualitas pelayanan berpengaruh signifikan terhadap promosi word of mouth dengan nilai nilai signifikansi $<0.001$

Kesimpulan : Ada pengaruh kualitas pelayanan terhadap peningkatan word of mouth di Klinik Pratama 'Aisyiyah Medical Center Surakarta

Kata Kunci :Kualitas Pelayanan kesehatan, Word of mouth, Klinik pratama
\end{abstract}

\section{ABSTRACT}

Background: Competition in health care business is getting higher. Healthcare services are competing to gain public trust in order for the community to actively participate in and trust in health services at clinics or health care providers. Marketing strategy word of mouth model is a form of promotion activities that are in need by service companies Objective: To know the effect of service quality on word of mouth improvement in Klinik Pratama 'Aisyiyah Medical Center Surakarta

Method: This research uses quantitative approach with regression statistical analysis from the results of questionnaires to test the hypothesis with word of mouth as variable dependent and service quality as independent variable

Result: Service quality significantly influence word of mouth promotion with significance value value $<0.001$

Conclusion: There is influence of service quality to word of mouth improvement in Klinik Pratama 'Aisyiyah Medical Center Surakarta a

Keywords: Quality of Health Services, Word of mouth, Pratama Clinic 


\section{PENDAHULUAN}

Perkembangan klinik di Indonesia terus meningkat seiring dengan berjalannya waktu. Jika dahulu klinik hanya didirikan oleh badan-badan keagamaan, sosial ataupun pemerintah tetapi sekarang banyak didirikan oleh berbagai badan usaha swasta yang berorientasi pada laba. Hal tersebut saat ini memunculkan persaingan-persaingan dalam penyelenggaraan pelayanan kesehatan. Jasa pelayanan kesehatan berlomba-lomba untuk mendapatkan kepercayaan masyarakat agar masyarakat ikut aktif dan mempercayai pelayanan kesehatan di klinik atau penyedia layanan kesehatan banyaknya klinik swasta yang berorientasi pada laba tersebut akan meningkatkan persaingan. Sehingga, untuk meningkatkan daya saing dalam industrinya diperlukan kualitas pelayanan yang mengarah pada tercapainya kepuasan dan loyalitas konsumen. Loyalitas konsumen dapat mengakibatkan tumbuhnya keinginan untuk melakukan pembelian ulang dan akan dengan sukarela merekomendasikan produk tersebut kepada orang lain yang disebut dengan word of mouth(Tjiptono, 2014).

Degan berkembangnya teknologi informasi yang semakin canggih maka model ataupun cara promosi penyedia layanan kesehatan juga mengalami perkembangan, promosi yang dilakukan di jejaringan sosial saat ini sedang trend dilakukan oleh penyedia layanan kesehatan ataupun layanan fisioterapi. Hal ini mengakibatkan orang terbuai dengan salah satu cara ataupun model promosi yang sangat sederhana yaitu word of mouth. Word of mouth merupakan model promosi yang tidak membutuhkan biaya atau gratis sehingga penulis tertarik untuk meneliti tentang pengaruh kualitas pelayanan terhadap peningkatan word of mouth di klinik pratama 'aisyiyah medical center surakarta

\section{A. TUJUAN}

Mengetahui pengaruh kualitas pelayanan terhadap peningkatan word of mouth di Klinik Pratama 'Aisyiyah Medical Center Surakarta

\section{B. METODE}

Penelitian ini menggunakan pendekatan kuantitatif dengan analisis statistik regresi,dari hasil pengisian kuesioner untuk menguji hipotesis dengan word of mouth sebagai variable dependent dan kualitas pelayanan sebagai variable independent. Dalam penelitian ini skala Likert dipakai sebagai alat ukur untuk mengukur variable penelitian. Tekhnik pengambilan dengan menggunakan teknik judgement sampling Menurut Notoadmojo (2012), judgement sampling adalah teknik penentuan sampel dengan mengambil sampel yang didasarkan pada pertimbangan. Populasi yang dipakai adalah seluruh pasien yang yang berkunjung ke klinik yaitu berjumlah 600 pasien. Sampel dalam penelitian ini adalah sebagian pasien yang menjalani 1 bulan periode penelitian dan memenuhi kriteria inklusi yaitu (1)Bersedia menjadi responden dengan menandatangani surat persetujuan menjadi responden,(2).Pasien yang mendapat pelayanan di Klinik pratama 'Aisyiyah Medical Center Surakarta dalam waktu yag ditetapkan,(3).Tidak mengalami gangguan fungsi kesadaran. Dan kriteria eksklusi yaitu (1). Menolak menjadi responden,(2)Pasien tidak kooperatif. (3)Pasien yang tidak bisa melakukan proses penelitian Penentuan jumlah sampel dengan menggunakan rumus $\mathrm{n}=$ $\mathrm{N} / 1+\mathrm{N}(\mathrm{e})^{2}$ dengan $\mathrm{n}=$ ukuran sampel $\mathrm{N}=$ ukuran populasi $\mathrm{e}=$ margin of eror, yaitu tingkat kesalahan maksimum yang dapat ditoleransi, dari rumus tersebut diperoleh hasil 85 responden. 


\section{HASIL DAN PEMBAHASAN \\ 1. KARAKTERISTIK RESPONDEN}

Tabel 1

Karakteristik Responden Berdasarkan Jenis Kelamin di Klinik Pratama Aisyiyah Medical Center

\begin{tabular}{|c|l|c|c|}
\hline No & \multicolumn{1}{|c|}{ JenisKelamin } & Jumlah & Persentase \\
\hline 1 & Laki-laki & 26 & $31 \%$ \\
\hline 2 & Perempuan & 59 & $69 \%$ \\
\hline & Jumlah & $\mathbf{8 5}$ & $\mathbf{1 0 0 \%}$ \\
\hline
\end{tabular}

Sumber : Hasil Analisis Data Primer, 2017.

Berdasarkan tabel karakteristik responden menurut jenis kelamin tersebut di atas menunjukkan bahwa jumlah responden yang paling banyak adalah perempuan yaitu sebanyak 59 (lima puluh sembilan ) responden. Hal ini menunjukkan bahwa wanita mempuyai resiko lebih tinggi untuk sakit dari pada laki-laki

Tabel 2

Karakteristik Responden Berdasarkan Umur Pasien di Klinik Pratama Aisyiyah Medical Center

\begin{tabular}{|c|c|c|c|}
\hline No & Umur & Jumlah & Persentase \\
\hline 1 & $\leq 16$ tahun & 11 & $13 \%$ \\
\hline 2 & 17-26tahun & 36 & $42 \%$ \\
\hline 3 & 27-36tahun & 27 & $32 \%$ \\
\hline 4 & > 36tahun & 11 & $13 \%$ \\
\hline & Jumlah & 85 & $100 \%$ \\
\hline
\end{tabular}

Sumber : Hasil Analisis Data Primer, 2017.

Berdasarkan tabel karakteristik responden menurut umur tersebut di atas menunjukkan bahwa jumlah responden yang paling banyak adalah berumur 17-26 tahun yaitu 36 responden. Hal ini menunjukkan bahwa keberadaan Klinik Pratama Aisyiyah Medical Center Surakarta yang tujuan awal adalah untuk memfasilitasi kesehatan mahasiswa di STIKES Aisyiyah Surakarta bisa sesuai tujuan awal untuk tujuan tersebut, karena rentang usia diatas adalah rentang usia mahasiswa di kampus tersebut. Sehingga perlu dilakukan pembenahan manajemen marketing untuk menarik pasien atau pengguna jasa klinik diluar institusi sendiri, karena saat ini klinik membuka pelayanan yang lebih luas atau pelayanan umum

Tabel 3

Karakteristik Responden Berdasarkan Tingkat Pendidikan Pasien di Klinik Pratama Aisyiyah Medical Center

\begin{tabular}{|c|l|c|c|}
\hline No & \multicolumn{1}{|c|}{ TingkatPendidikan } & Jumlah & Persentase \\
\hline 1 & SMP & 6 & $7 \%$ \\
\hline 2 & SMA & 33 & $39 \%$ \\
\hline 3 & Diploma (D3) & 22 & $26 \%$ \\
\hline
\end{tabular}




\begin{tabular}{|c|l|c|c|}
\hline 4 & Sarjana (S1) & 13 & $15 \%$ \\
\hline 5 & Pasca Sarjana (S2) & 11 & $13 \%$ \\
\hline & Jumlah & $\mathbf{8 5}$ & $\mathbf{1 0 0} \%$ \\
\hline
\end{tabular}

Berdasarkan tabel karakteristik responden menurut tingkat pendidikan tersebut di atas menunjukkan bahwa responden yang paling banyak adalah lulusan SMA yaitu sebanyak 33 responden. Hal ini berarti pasien di klinik yang dari luar mahasiswa menunjukkan kurang sekali karena masih rendah, sehingga promosi ataupun manajemen marketing untuk menyasar segmen pengguna dengan tingkat pendidikan yang bervariatif bisa tercapai. Adanya pengguna klinik dengan tingkat pendidikan SMA menjadi pengguna terbanyak menunjukkan bahwa keberadaan Klinik Pratama Aisyiyah Medical Center Surakarta yang tujuan awal adalah untuk memfasilitasi kesehatan mahasiswa di STIKES Aisyiyah Surakarta bisa tercapai.

Tabel 4

Karakteristik Responden Berdasarkan Jenis Pekerjaan Pasien di Klinik Pratama Aisyiyah Medical Center

\begin{tabular}{|c|l|c|c|}
\hline No & \multicolumn{1}{|c|}{ Jenis Pekerjaan } & Jumlah & Persentase \\
\hline 1 & Pelajar/Mahasiswa & 48 & $56 \%$ \\
\hline 2 & KaryawanSwasta & 27 & $32 \%$ \\
\hline 3 & Pegawai Negeri Sipil & 10 & $12 \%$ \\
\hline & Jumlah & $\mathbf{8 5}$ & $\mathbf{1 0 0 \%}$ \\
\hline
\end{tabular}

Sumber : Hasil Analisis Data Primer, 2017.

Berdasarkan tabel karakteristik responden menurut jenis pekerjaan tersebut di atas menunjukkan bahwa responden yang paling banyak adalah yang mempunyai jenis pekerjaan sebagai pelajar/mahasiswa yaitu sebanyak 48 responden. Adanya pasien dengan kategori jenis pekerjaan dengan jenis pekerjaan pelajar / mahasiswa hal ini menunjukkan biaya yang murah menjadi prioritas dalam pelayanan kesehatan, karena ditinjau dari jenis pekerjaan tersebut pelajar / mahasiswa adalah termasuk jenis pekerjaan yang belum mempunyai penghasilan yang cukup.

\section{HASIL PENELITIAN}

Pengujian normalitas data menggunakan One-Sampel Kolmogrov-Smirnov test. Tingkat signifikansi yang digunakan adalah $5 \%$. Uji statistik yang penulis lakukan guna mengetahui normalitas residual adalah uji statistik non-parametrik One-Sampel Kolmogrov-Smirnov test.. hasil yang diperoleh adalah nilai probabilitas menjadi 0.915 yang nilainya lebih besar dari signifikansi 0.05 . Hal ini berarti $H_{0}$ diterima yang berarti data residual berdistribusi normal

Uji heterokesdastisitas dalam penelitian ini diuji dengan scaterplots. Hasil uji heteroskedastisitas variabel dependen promosi word of mouth menunjukan bahwa titiktitik tersebar di atas dan dibawa angka nol. Titik-titik menyebar dan tidak membentuk pola tertentu yang teratur sehingga dapat disimpulkan bahwa dalam model regresi tidak terjadi heteroskedastisitas

Dari uji ANOVA atau $F$ test didapat nilai $f$ hitung sebesar 59.403 dengan nilai probabilitas nilai signifikansi $<0,001$. Oleh karena nilai signifikansi ini lebih kecil dari 0,001 .hal ini berarti kualitas jasa mempunyai pengaruh yang signifikan terhadap promosi word of mouth . 
Tabel 5 Uji Regeresi

\begin{tabular}{|l|c|r|r|c|}
\hline Model & $\mathrm{R}$ & R Square & \multicolumn{1}{|c|}{$\begin{array}{c}\text { Adjusted R } \\
\text { Square }\end{array}$} & $\begin{array}{c}\text { Std. Error of the } \\
\text { Estimate }\end{array}$ \\
\hline 1 & $.646^{\mathrm{a}}$ & .417 & .410 & .463518 \\
\hline
\end{tabular}

\begin{tabular}{|c|c|c|c|c|c|}
\hline \multirow[b]{2}{*}{ Model } & \multicolumn{2}{|c|}{$\begin{array}{c}\text { Unstandardized } \\
\text { Coefficients }\end{array}$} & \multirow{2}{*}{$\begin{array}{c}\begin{array}{c}\text { Standardized } \\
\text { Coefficients }\end{array} \\
\text { Beta }\end{array}$} & \multirow[b]{2}{*}{$\mathrm{t}$} & \multirow[b]{2}{*}{ Sig. } \\
\hline & $\mathrm{B}$ & Std. Error & & & \\
\hline (Constant) & .662 & .426 & & 1.552 & .124 \\
\hline $\begin{array}{l}\text { kualitas } \\
\text { pelayanan }\end{array}$ & .851 & .110 & .646 & 7.707 & .000 \\
\hline
\end{tabular}

Hasil uji regresi menunjukan nilai $R^{2}$ sebesar 0,417 atau $41.7 \%$. Hal ini menunjukan 41.7 $\%$ promosi word of mouth dapat dijelaskan oleh variabel independen kualitas pelayanan Sedangkan sisanya dijelaskan oleh faktor lain diluar model penelitian

Variabel kualitas jasa mempunyai nilai t hitung sebesar 7.707 dan nilai signifikansi $<0.001$. Hal ini berarti kualitas pelayanan berpengaruh signifikan terhadap promosi word of mouth. Koefisien bertanda positif $(0.815>0)$. Artinya semakin baik kualitas jasa maka akan semakin baik pula hasil promosi word of mouth, demikian pula sebaliknya.

Berdasarkan data statistik yang telah dilakukan dapat disimpulkan bahwa. Ada pengaruh kualitas pelayanan terhadap peningkatan word of mouth di Klinik Pratama 'Aisyiyah Medical Center Surakarta. Pengaruh untuk kualitas pelayanan adalah semakin jasa pelayanan baik maka word of mouth oleh pasien kepada masyarakat atau calon pasien semakin tinggi dan sebaliknya semakin jasa pelayanan buruk maka adanya word of mouth oleh pasien kepada masyarakat atau calon pasien semakin rendah. Hal diatas bisa terjadi karena word of mouth bisa dilakukan oleh konsumen karena adanya kepuasan dari konsumen atau pasien, sementara kepuasan dari pasien ditentukan oleh beberapa faktor salahsatunya adalah kualitas pelayanan. Taghizadeh, et al (2013) dan Wijayanto (2012) menyimpulkan bahwa komunikasi Word of Mouth dipengaruhi oleh kualitas pelayanan. Kotler \& Keller (2008) mengemukakan bahwa kualitas pelayanan merupakan faktor yang utama dalam memperoleh kepuasan konsumen, sementara itu kepuasan konsumen mempengarui seseorang dalam melakukan word of mouth

Menurut Kotler \& Keller (2008), pemasaran produk/jasa yang dihasilkan tidak hanya membutuhkan pemasaran eksternal tetapi juga pemasaran internal dan interaktif. Pemasaran ekternal menggambarkan pekerjaan normal yang dilakukan oleh perusahaan, menyiapkan pelayanan prima, memberi biaya, mendistribusikan dan mempromosikan jasa itu kepada konsumen. Pemasaran internal menjelaskan pekerjaan yang dilakukan oleh perusahaan untuk melatih dan memotivasi pegawainya untuk melayani pelanggan dengan baik. Pemasaran interaktif menggambarkan keahlian pegawai dalam melayani pelanggan. Word of Mouth merupakan sebuah strategi marketing yang bisa dikembangkan dalam rangka meningkatkan jumlah pasien.Menurut

Hughes (2007) menyatakan efektivitas komunikasi Word of Mouth secara umum dipengaruhi oleh empat faktor yakni (1). Faktor Emosional. Faktor emosional dalam diri seseorang dapat ditimbulkan oleh informasi yang diperoleh melalui komunikasi Word of Mouth seperti keinginan atau kebutuhan terhadap suatu produk atau jasa. Munculnya suatu keinginan atau kebutuhan tersebut, dapat memotivasi seseorang untuk sampai 
pada pengambilan keputusan untuk menggunakan suatu produk atau jasa tertentu. . Menurut Siverman (2011) emosi yang menunjukkan perasaan individu tidak hanya dilihat dari dimensi senang atau tidak senang. Secara lebih jauh, Siverman mengkategorikan emosional menjadi 3 (tiga) dimensi yaitu perasaan yang menyenangkan atau tidak menyenangkan, excited atau innert feeling, dan expectancy atau release feeling. Dalam dimensi excited, perasaan yang dialami oleh individu dapat disertai dengan tingkah laku atau perbuatan secara nyata. Sementara dalam dimensi expectancy, perasaan yang dialami oleh individu sebagai sesuatu yang masih dalam pengharapan, namun ada pula perasaan individu ditimbulkan oleh keadaan yang telah terjadi atau nyata.Emosi karena adanya suatu kepuasan akan pelayanan jasa seperti pelayanan kesehatan menumbuhkan sikap word of mouth, dimana pasien secara emosional akan menceritakan apa yang dirasakan

Faktor yang ke (2) adalah faktor Kognisi. Faktor kognisi adalah mencakup ketidakpastian terhadap suatu produk atau jasa dapat menjadikan komunikasi Word of Mouth menjadi efektif. Dalam arti, bahwa seseorang akan berusaha mencari infomasi yang lebih memadai tentang suatu produk atau jasa terutama melalui komunikasi Word of Mouth. Untuk memberikan respon yang tepat, maka individu harus memiliki hubungan stimulus dan respon yang lebih banyak yang dapat dipcroleh dari hasil pengalaman yang diperolehnya dan hasil respon-respon yang telah lalu. Faktor kognisi dalam diri individu terdiri dari dua unsur yaitu general ability dan special ability. Unsur general ability yang terdapat pada masing-masmg individu berbeda. Sementara unsur special ability merupakan unsur yang bersifat khusus yakni mengenai bidang tertentu (Hughes, 2007).

Faktor yang ke (3) adalah Opinion Leader. Opinion leader dapat mempengaruhi efektivitas komunikasi Word of Mouth. Opinion leader yang dimaksudkan adalah orang-orang yang dapat ditanyai dan dimintai informasi karena keahlian, pengetahuan, komunikasi yang luas, dan rujukan yang kuat yang dimiliki oleh seseorang dibandingkan yang lainnya. Opinion leader merupakan orang yang dalam komunikasi informal berhubungan dengan produk yang memberikan saran atau informasi tentang produk tertentu. Untuk menjangkau opinion leader, maka perlu melakukan identifikasi ciri-cin kepemimpinan opini melalui mengidentifikasi media yang dibaca oleh pemimpin opini dan mengarahkan iklan atau promosi kepada pemimpin opini (Kotler, 2014).

Sehubungan dengan hal tersebut, dalam komunikasi Word of Mouth terdapat adanya suatu jaringan informasi yang disebut dengan network hubs yakni individu yang berkomunikasi dengan lebih banyak individu lain mengenai suatu produk dibandingkan dengan rata-rata individu lain. Kualitas pelayanan merupakan factor pemicu adanya word of mouth (Hughes, 2007).

\section{KESIMPULAN}

Berdasarkan hasil analisis data dan pembahasan hasil penelitian yang telah diuraikan diatas, maka hasil penelitian ini dapat ditarik kesimpulan bahwa terdapat pengaruh kualitas pelayanan terhadap peningkatan word of mouth di Klinik Pratama 'Aisyiyah Medical Center Surakarta 


\section{DAFTAR PUSTAKA}

Hughes, Mark. 2007. Buzz marketing. Jakarta . PT Elex Media Computindo

Kotler, Philip dan Keller, Kevin Lane. 2008. Manajemen Pemasaran. Jakarta. Erlangga.

Kotler, Philip. 2014. Manajamen Pemasaran . Jakarta. PT. Indeks Kelompok Gramedia.

Notoatmodjo,S. 2012. Metodologi Penelitian Kesehatan. Jakarta: Rineka Cipta

Siverman, George. 2011. The Secret Of Word Of Mouth Marketing. New York. Amacom.

Taghizadeh, Houshang. Taghipourian, Mohammad and Khazaei. Amir. 2013. The Effect of Customer

Satisfaction on Word of Mouth Communication. Research Journal of Applied Sciences, Engineering and Technology 5(8): 2569-2575, 2013

Tjiptono, Fandy. 2014. Pemasaran Jasa. Jakarta.Gramedia Cawang.

Wijayanto, Dian. 2012. PengantarManajemen. Jakarta: Gramedia Pustaka Utama 